\title{
Serum folate concentrations at diagnosis are associated with hepatocellular carcinoma survival in the Guangdong Liver Cancer Cohort study
}

\author{
Ai-Ping Fang ${ }^{1,2}$, Zhao-Yan Liu ${ }^{1}$, Gong-Cheng Liao ${ }^{1}$, Pei-Yan Chen ${ }^{1}$, Xiao-Yan Wang ${ }^{1}$, Dao-Ming Zhang ${ }^{1}$, \\ Yun $\mathrm{Luo}^{1}$, Jing-An Long ${ }^{1}$, Rong-Huan Zhong ${ }^{1}$, Zhong-Guo Zhou ${ }^{3,4}$, Yan-Jun $\mathrm{Xu}^{5}$, Xiao-Jun Xu', \\ Wen-Hua Ling ${ }^{1,2}$, Min-Shan Chen ${ }^{3,4}$, Yao-Jun Zhang ${ }^{3,4 *}$ and Hui-Lian Zhu ${ }^{1,2 *}$ \\ ${ }^{1}$ Department of Nutrition, School of Public Health, Sun Yat-sen University, Guangzhou, People's Republic of China \\ ${ }^{2}$ Guangdong Provincial Key Laboratory of Food, Nutrition and Health, School of Public Health, Sun Yat-sen University, \\ Guangzhou, People's Republic of China \\ ${ }^{3}$ Department of Hepatobiliary Oncology, Sun Yat-sen University Cancer Center, Guangzhou, People's Republic of China \\ ${ }^{4}$ State Key Laboratory of Oncology in South China, Sun Yat-sen University Cancer Center, Guangzhou, People's Republic of China \\ ${ }^{5}$ Department of Chronic Noncommunicable Disease Prevention and Control, Guangdong Provincial Center for Disease Control \\ and Prevention, Guangzhou, People's Republic of China
}

(Submitted 30 August 2018 - Final revision received 1 February 2019 - Accepted 4 March 2019 - First published online 17June 2019)

\section{Abstract}

Existing data on folate status and hepatocellular carcinoma (HCC) prognosis are scarce. We prospectively examined whether serum folate concentrations at diagnosis were associated with liver cancer-specific survival (LCSS) and overall survival (OS) among 982 patients with newly diagnosed, previously untreated HCC, who were enrolled in the Guangdong Liver Cancer Cohort (GLCC) study between September 2013 and February 2017. Serum folate concentrations were measured using chemiluminescent microparticle immunoassay. Cox proportional hazards models were performed to estimate hazard ratios (HR) and $95 \%$ CI by sex-specific quartile of serum folate. Compared with patients in the third quartile of serum folate, patients in the lowest quartile had significantly inferior LCSS (HR $=1 \cdot 48 ; 95 \%$ CI 1.05, 2.09) and OS (HR $=1 \cdot 43$; $95 \%$ CI $1.03,1.99)$ after adjustment for non-clinical and clinical prognostic factors. The associations were not significantly modified by sex, age at diagnosis, alcohol drinking status and Barcelona Clinic Liver Cancer (BCLC) stage. However, there were statistically significant interactions on both multiplicative and additive scale between serum folate and C-reactive protein (CRP) levels or smoking status and the associations of lower serum folate with worse LCSS and OS were only evident among patients with CRP > 3.0 mg/l or current smokers. An inverse association with LCSS were also observed among patients with liver damage score $\geq 3$. These results suggest that lower serum folate concentrations at diagnosis are independently associated with worse HCC survival, most prominently among patients with systemic inflammation and current smokers. A future trial of folate supplementation seems to be promising in HCC patients with lower folate status.

\section{Key words: Folate status: Hepatocellular carcinoma: Survival: Mortality: Prospective studies}

Primary liver cancer (PLC) is the second leading cause of cancer-related deaths worldwide ${ }^{(1)}$. Despite enormous progress in the modern therapeutic era, it remains a generally incurable disease with 5-year net survival ranging from 5\% to $30 \%{ }^{(2)}$. Hepatocellular carcinoma (HCC) is the most common subtype, accounting for approximately $90 \%$ of PLC cases $^{(3)}$. Tumour stage, general health, hepatic function and anticancer therapy are main prognostic indicators for HCC survival $^{(4)}$. However, the role of other predictive factors including diet and nutrition in HCC prognosis has been largely unexplored.

Folate, a water-soluble B vitamin, involved in one-carbon metabolism, has been related to cancer development and progression $^{(5)}$. Folate functions as a conveyor of one-carbon units in the formation of nucleotides and methionine, whose deficiency can impair DNA synthesis, repair and methylation and thereby promote carcinogenesis ${ }^{(6)}$. In addition, tumour cells require more folate than normal cells to maintain rapid DNA replication and cell

Abbreviations: ALP, alkaline phosphatase; BCLC, Barcelona Clinic Liver Cancer; CRP, C-reactive protein; GGT, $\gamma$-glutaryl-transferase; GLCC, Guangdong Liver Cancer Cohort; HBsAg, hepatitis B surface antigen; HCC, hepatocellular carcinoma; HR, hazard ratio; LCSS, liver cancer-specific survival; OS, overall survival; PLC, primary liver cancer; SYSUCC, Sun Yat-sen University Cancer Center.

* Corresponding authors: Yao-Jun Zhang, email zhangyuj@sysucc.org.cn; Hui-Lian Zhu, email zhuhl@mail.sysu.edu.cn 


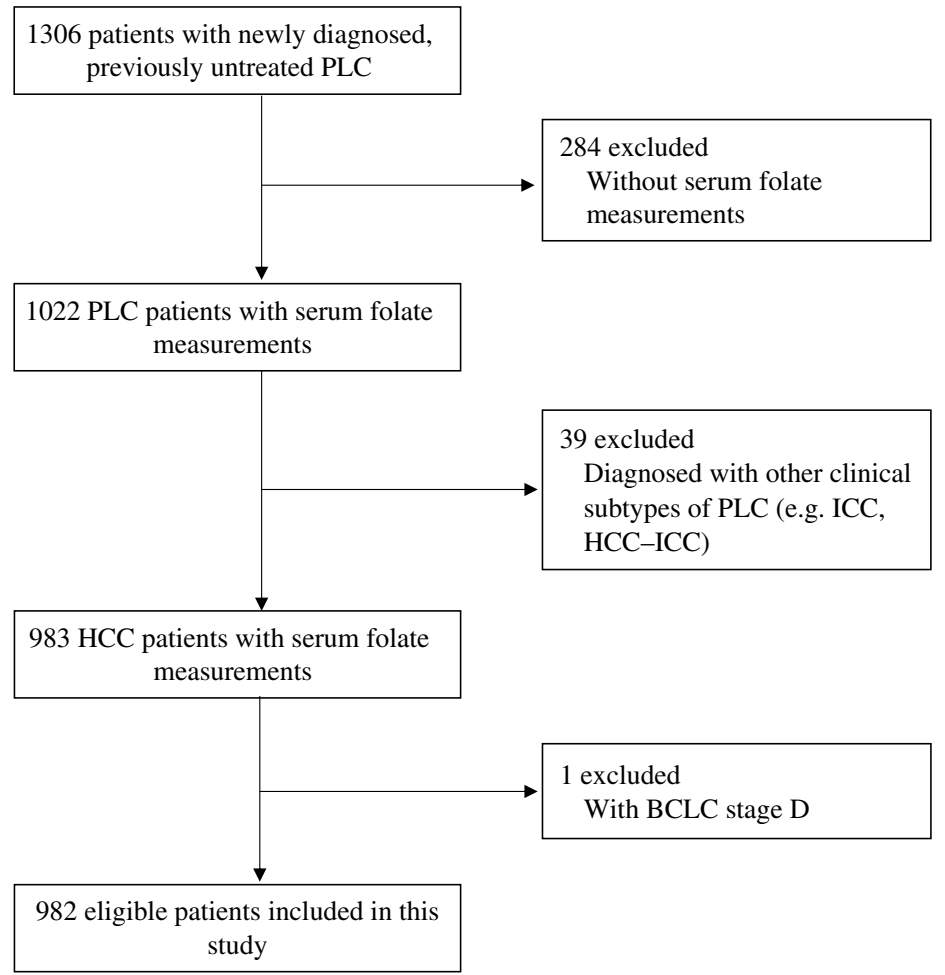

Fig. 1. Flow chart of participant selection from the Guangdong Liver Cancer Cohort study. PLC, primary liver cancer; HCC, hepatocellular carcinoma; ICC, intrahepatic cholangiocarcinoma; BCLC, Barcelona Clinic Liver Cancer.

proliferation, and excess folate may enhance tumour growth ${ }^{(7)}$. The liver is responsible for storage and metabolism of folate. Experimental evidence has suggested that dietary methyl deficiency in folate and other one-carbon donors can induce the development of liver cancer through induction of oxidative damage, alteration of lipid metabolism and epigenetic abnormality; ${ }^{(8,9)}$ whereas folic acid supplementation can inhibit angiogenesis during early hepatocarcinogenesis ${ }^{(10,11)}$, and withdrawal of folate can suppress hepatoma cell growth ${ }^{(12)}$. Three case-control studies have reported an inverse association between circulating folate concentrations and the risk of $\mathrm{HCC}^{(13-15)}$. A prospective cohort study observed that hepatitis B surface antigen (HBsAg)-positive participants with lower folate concentrations were at increased risk of developing liver damage and $\mathrm{HCC}^{(16)}$. Another large prospective cohort study also showed a protective effect of higher folate intake on HCC incidence among 494743 healthy adults who participated in the National Institutes of Health-American Association of Retired Persons (NIH-AARP) Diet and Health Study ${ }^{(17)}$.

Folate status has been linked with cancer mortality in many epidemiological studies ${ }^{(18-21)}$. Specific to HCC prognosis, however, the only existing evidence found that lower plasma folate concentrations were associated with inferior overall survival (OS) among 160 HCC patients with a median plasma folate concentration of $12 \cdot 2 \mathrm{ng} / \mathrm{ml}^{(22)}$. Of note, the study was conducted in the USA, where mandatory food fortification with folic acid has been implemented since $1998^{(23)}$. As we all know, circulating folate concentrations vary substantially across the world due to the difference in diet, lifestyle, food-fortification practices and dietary supplement use ${ }^{(24)}$. Asians had almost half the circulating folate concentration of Americans (12.4 v. $28.5 \mathrm{nmol} / \mathrm{l}$; to convert to $\mathrm{ng} / \mathrm{ml}$, divide by $2 \cdot 27)^{(24)}$, which possibly places Asian populations at increased risk of cancer incidence and mortality. Given that China alone accounts for around $50 \%$ of the total numbers of PLC cases and deaths globally ${ }^{(1)}$, investigation of the influence of folate status on HCC prognosis in Chinese populations represents a high-priority research area.

In the present study, we prospectively examined whether serum folate concentrations at diagnosis were associated with survival outcomes among a large sample size of Chinese patients with newly diagnosed HCC enrolled into the Guangdong Liver Cancer Cohort (GLCC) study.

\section{Subjects and methods}

\section{Study population}

The GLCC, an ongoing, prospective cohort study, was established in 2013 at Sun Yat-sen University Cancer Center (SYSUCC). It is designed to identify genetic and environmental factors that affect the progression and prognosis of PLC. As previously described $^{(25)}$, first incident PLC patients who have not yet initiated cancer treatment were enrolled within $30 \mathrm{~d}$ of diagnosis. PLC diagnosis was verified in the SYSUCC Clinical Information Presentation System according to the National Comprehensive Cancer Network (NCCN) Clinical Practice Guidelines in Oncology: Hepatobiliary Cancers ${ }^{(26)}$. Written informed consent was provided by all participants. The study was approved by the institutional review board of School of Public Health at the Sun Yat-sen University.

Between September 2013 and February 2017, we enrolled 1306 eligible patients into the GLCC. After excluding 324 patients who had no available serum samples for folate measurements, were diagnosed with PLC other than HCC (e.g. 
intrahepatic cholangiocarcinoma (ICC) and HCC-ICC) or had the Barcelona Clinic Liver Cancer (BCLC) stage D, we finally included 982 patients with newly diagnosed, previously untreated HCC in the present study. Detailed participant selection is shown in Fig. 1. The included patients did not differ by demographics and lifestyle characteristics from the patients excluded from the analysis (Supplementary Table S1). Among the included patients, $59.6 \%$ of the patients were pathologically confirmed.

\section{Laboratory analyses}

Peripheral venous blood was drawn after overnight fasting prior to anticancer therapy. Serum samples were separated into aliquots, and stored in $-80^{\circ} \mathrm{C}$ freezers. Serum folate measurements were batched and made using a chemiluminescent microparticle immunoassay (ARCHITECT Folate assay, Abbott Diagnostics) at the KingMed Diagnostics Laboratory (Guangzhou, China). All laboratory personnel were blinded, and multiple masked quality control samples were interspersed among the case samples. The intra-assay $\mathrm{CV}$ was $7.7 \%$ for blinded, replicate, quality control samples.

Routine laboratory parameters, including HBsAg and antibodies to hepatitis $\mathrm{C}$ virus (anti-HCV), alanine aminotransferase (ALT), aspartate aminotransferase (AST), $\gamma$-glutamyltransferase (GGT), alkaline phosphatase (ALP), albumin, total bilirubin (TBIL), $\alpha$-fetoprotein (a tumour marker) and C-reactive protein (CRP, a marker for systemic inflammation), were measured at the Clinical Laboratory of SYSUCC.

\section{Clinical and lifestyle data collection}

Detailed demographic, diagnostic and treatment information was extracted from the SYSUCC electronic clinical and administrative databases. Three predictors were employed to assess preexisting chronic liver diseases: (1) HBsAg and anti-HCV, (2) Child-Pugh score ${ }^{(27,28)}$ and (3) liver damage score ${ }^{(29)}$, a summary score of the number of abnormal laboratory-defined values for six liver function tests (ALT $>50 \mathrm{U} / 1$, AST $>40 \mathrm{U} / 1$, GGT $>60 \mathrm{U} / 1$, ALP $>150 \mathrm{U} / 1$, albumin $<40 \mathrm{~g} / 1$ and TBIL $>20 \cdot 5 \mu \mathrm{mol} / \mathrm{l}$ ). The BCLC stage was chosen to assess tumour progression, which comprehensively considers tumour number and size, Child-Pugh score and performance status of the patient ${ }^{(30)}$. Information on lifestyles, e.g. daily activity, smoking status, alcohol drinking status and multivitamin use, was obtained through baseline interviews. Daily activity was assessed by summing the products of time spent on a variety of activities (e.g. work, transportation, housework, physical exercises and leisure sedentary activity) with the mean metabolic equivalent (MET) for that activity. Dietary information was collected using a validated seventynine-item semi-quantitative $\mathrm{FFQ}^{(31)}$. Patients were asked how often (never, per year, per month, per week, or per d) they had consumed each food item on average in the previous year before diagnosis. Nutrient intakes were estimated by multiplying the frequency of consumption of each food item by its nutrient content per portion size according to the China Food Composition Database ${ }^{(32,33)}$. Dietary folate intake was standardised to $2000 \mathrm{kcal}(8368 \mathrm{~kJ})$ using the residual method $^{(34)}$. Anthropometric measures were collected by nurses following a standard procedure with the same calibrated equipment. BMI was calculated as weight $(\mathrm{kg})$ divided by height squared $\left(\mathrm{m}^{2}\right)$.

\section{Survival measurements}

Survival outcomes assessed included liver cancer-specific survival (LCSS) and OS in this analysis. The former considers death due to HCC, and the latter considers death from any cause. Follow-up began at the time of HCC diagnosis until the occurrence of a death event, and a patient without an event of interest during the follow-up was censored at the last known date alive or at the time of last outcome ascertainment (26 September 2017). Deaths were ascertained through reviewing medical records and by telephone interview with next-of-kin every 6 to 12 months. Identification number or full name in combination with date of birth of persistent non-responders was searched in the National Death Registration System. The underlying cause of death was assigned from death certificates per the International Classification of Diseases-10 codes.

\section{Statistical analysis}

To investigate the association of folate status with LCSS and OS, we divided the patients into four groups according to sex-specific quartiles of serum folate concentrations. Demographic and clinical characteristics were compared across quartiles of serum folate using ANOVA for normally distributed continuous variables, the Kruskal-Wallis tests for skewed distributed continuous variables and the $\chi^{2}$ test for categorical variables. Mortality rate expressed as per 10000 person-days was calculated as the number of deaths divided by the total person-days during follow-up. Cox proportional hazards models were used to calculate hazard ratios (HR) and $95 \% \mathrm{CI}$ with the third quartile as the reference category. We first adjusted for non-clinical factors (age at diagnosis, sex (women, men), BMI, smoking status (never, former, current) and alcohol drinking status (never, former, current)), and then additionally adjusted for clinical prognostic factors (CRP levels ( $\leq 3.0 \mathrm{mg} / \mathrm{l},>3.0 \mathrm{mg} / \mathrm{l})$, liver damage score $(0,1-2, \geq 3)$, BCLC stage $(0, \mathrm{~A}, \mathrm{~B}, \mathrm{C})$ and cancer treatment (hepatectomy/liver transplantation, local ablation, hepatic arterial intervention, other treatments)). Other potential confounders, such as education level, residence and payment for medical care, only marginally changed the results and were thus excluded in the multivariate models. In the LCSS analysis, death from HCC was the endpoint, and death due to other causes was censored. In the OS analysis, death from any cause was the endpoint. Proportional hazard assumption was satisfied by including a time-dependent variable, which was the cross-product of folate and time. Tests for linear trend were based on the integer scores of different quartiles of serum folate (from 1 to 4). Non-linearity was tested with restricted cubic splines ${ }^{(35)}$, which was not significant. Covariates with missing observations were imputed by the multiple imputation method. Similar results were obtained when restricted to non-missing data.

Multiplicative interactions were assessed by entering main effect terms, a cross-product term of the serum folate quartile and the stratification variable into the model and were evaluated using likelihood ratio tests based on the models with and without the interaction terms. Selected stratification variables included sex, age at diagnosis ( $<45$ years, $45-60$ years, $\geq 60$ years), CRP 
levels ( $\leq 3.0 \mathrm{mg} / 1,>3.0 \mathrm{mg} / \mathrm{l})$, liver damage score $(0,1-2, \geq 3)$, BCLC stage (0-A, B-C), smoking status (never, former, current) and alcohol drinking status (never, former, current). Stratified analyses were thereafter performed using the initial quartile cut-offs for the entire cohort. For statistically significant multiplicative interactions, we further conducted interactions on an additive scale to estimate the departure from additivity of effects using the relative excess risk due to interaction and the attributable proportion due to interaction ${ }^{(36)}$. The delta method was used to obtain CI for the indices ${ }^{(37)}$.

Statistical analyses were performed using SAS software version 9.4 (SAS Institute). A two-sided value of $P<0.05$ was considered of statistical significance.

\section{Results}

\section{Patient characteristics}

Of the 982 patients, there were $868(88.4 \%)$ men. Mean age was 52.9 (SD 11.8) years. Median serum folate concentration was $7 \cdot 13$ (25th-75th percentile $5 \cdot 34-9 \cdot 42$ ) ng/ml. At the time of sampling, $2 \cdot 2 \%$ of patients fulfilled the clinical nutritional criteria for severe folate deficiency $(<3 \mathrm{ng} / \mathrm{ml})$, and a further $32.2 \%$ were classified as marginal folate deficiency (3-6 ng/ml). Among the 674 patients who had completed the FFQ, average intake of energy and energy-adjusted dietary folate were 2003 (sD 589) $\mathrm{kcal} / \mathrm{d}(8381$ (sD 2464) kJ/d) and 197.9 (sD 79.7) $\mu \mathrm{g} / \mathrm{d}$, respectively. Detailed demographic, clinical and treatment characteristics of the study population by sex-specific quartiles of serum folate are listed in Table 1. Patients in the highest quartile of serum folate were more educated, were less likely to be smokers, were more likely to be diagnosed with fatty liver disease and diabetes mellitus, had less severe liver damage (mainly driven by GGT, ALP and albumin) and systemic inflammation and less advanced BCLC stage, and were more likely to receive surgery in comparison with patients in the lowest quartile. An increasing trend of energy-adjusted dietary folate intake across quartiles of serum folate was observed ( $P=0.01$ for trend). Only $4.8 \%$ of the patients reported using multivitamin supplements in the previous year and there was no significant difference in multivitamin use across quartiles of serum folate in 709 patients with available supplement use data. Other characteristics did not significantly differ by quartiles of serum folate.

\section{Serum folate and hepatocellular carcinoma survival}

During a median of 463 (25th-75th percentile: $225-828) \mathrm{d}$ of follow-up and 531927 person-days at risk, 319 deaths (32.5\%) were documented, including 292 (91.5\%) from HCC. The associations between sex-specific quartiles of serum folate and survival outcomes are shown in Table 2. Both liver cancer-specific and overall mortality rates were highest in the first quartile and lowest in the third quartile of serum folate. In multivariable analyses with adjustment for non-clinical factors (age at diagnosis, sex, BMI, smoking and alcohol drinking status), compared with the third quartile of serum folate, the adjusted HR in the lowest quartile was 2.08 (95\% CI 1.49, 2.90) for LCSS and 2.01 (95\% CI 1.46 , 2.76) for OS. The associations with LCSS and OS remained statistically significant after additional adjustment for clinical prognostic factors including CRP levels, liver damage score, BCLC stage and cancer treatment. The adjusted HR in the first ( $v$. third) quartile of serum folate were 1.48 (95\% CI 1.05, 2.09) for LCSS and 1.43 (95\% CI $1.03,1.99)$ for OS in the fully adjusted models.

\section{Interactions and stratified analyses}

The influence of serum folate concentrations across strata of selected factors is presented in Table 3. The relation between serum folate concentrations and LCSS or OS remained similar across strata of sex, age at diagnosis, alcohol drinking status and BCLC stage (all $P>0 \cdot 10$ for interaction). There were statistically significant multiplicative interactions between sex-specific quartiles of serum folate and CRP levels or smoking status on associations with both LCSS and OS (all $P \leq 0.01$ for interaction). When stratified by CRP levels, serum folate concentrations were inversely associated with LCSS and OS among patients who had CRP $>3.0 \mathrm{mg} / 1$ (all $P=0.01$ for trend), but not among those with $\mathrm{CRP} \leq 3.0 \mathrm{mg} / \mathrm{l}$ (all $P>0.05$ for trend). Fig. 2 shows the joint effects of serum folate and CRP levels on HCC survival controlling for potential confounders. Compared with patients without systemic inflammation $(\mathrm{CRP} \leq 3.0 \mathrm{mg} / \mathrm{l})$ in the higher serum folate category ( $\geq$ median), the HR were 1.91 (95\% CI 1.34, 2.71) for LCSS and 1.90 (95\% CI $1 \cdot 36,2 \cdot 65$ ) for OS in patients with systemic inflammation (CRP $>3.0 \mathrm{mg} / \mathrm{l}$ ) and lower serum folate concentrations (<median). When stratified by smoking status, the inverse association of serum folate concentrations with LCSS or OS was only evident among current smokers (Table 3, all $P=0.04$ for trend) rather than never or former smokers (all $P>0.05$ for trend). The joint effects of serum folate concentrations and smoking status on survival outcomes are presented in Fig. 3. Current smokers in the lower serum folate category (<median) had significantly inferior LCSS $(\mathrm{HR}=$ $1 \cdot 44,95 \%$ CI $1 \cdot 02,2 \cdot 04)$ and OS (HR $=1 \cdot 45,95 \%$ CI $1 \cdot 05,2 \cdot 01)$ in comparison with never/former smokers with higher serum folate concentrations ( $\geq$ median). According to Fig. 2 and 3, the relative excess risk due to interactions and attributable proportion due to interactions indicate positive effect modification of lower serum folate concentrations with systemic inflammation or current smoking on an additive scale and the ratio of HR suggests positive interaction on a multiplicative scale in the association with LCSS and OS. In addition, lower serum folate concentrations were associated with worse LCSS among patients who had liver damage score $\geq 3$ (Table $3, P=0.04$ for trend), although no significant multiplicative interaction was observed between serum folate and preexisting liver damage $(P=0.09$ for interaction).

\section{Discussion}

To our knowledge, this is the largest cohort study assessing folate status in relation to HCC survival. In addition, this is the first prospective study evaluating the association between serum folate concentrations and HCC prognosis in nonCaucasian populations and in populations without mandatory food fortification with folic acid and widespread folate-containing supplement use. In this prospective cohort study of 982 HCC patients, we observed that lower serum folate concentrations at diagnosis were associated with inferior LCSS and OS. These findings did not vary substantially across strata of sex, age at diagnosis, alcohol drinking status and BCLC stage. 
Table 1. Baseline characteristics of participants by sex-specific quartiles $(Q)$ of serum folate concentrations in the Guangdong Liver Cancer Cohort study

\begin{tabular}{|c|c|c|c|c|}
\hline & \multicolumn{4}{|c|}{ Sex-specific quartile of serum folate } \\
\hline & Q1 (n 243) & Q2 (n 247) & Q3 (n 245) & Q4 (n 247) \\
\hline \multicolumn{5}{|l|}{ Serum folate $(\mathrm{ng} / \mathrm{ml})$} \\
\hline \multicolumn{5}{|l|}{ Range } \\
\hline Women & $2 \cdot 64-6 \cdot 91$ & $6 \cdot 92-9 \cdot 30$ & $9 \cdot 31-11 \cdot 18$ & $11 \cdot 19-19.51$ \\
\hline Men & $1.63-5.19$ & $5 \cdot 20-6 \cdot 87$ & $6 \cdot 88-9 \cdot 14$ & $9 \cdot 15-19 \cdot 74$ \\
\hline \multicolumn{5}{|l|}{ Age at diagnosis (years) } \\
\hline Mean & $52 \cdot 7$ & $52 \cdot 9$ & 53.2 & $52 \cdot 8$ \\
\hline SD & $12 \cdot 8$ & 11.8 & 11.6 & 11.0 \\
\hline Men (\%) & 88.5 & 88.3 & 88.6 & 88.3 \\
\hline \multicolumn{5}{|l|}{ BMl at entry $\left(\mathrm{kg} / \mathrm{m}^{2}\right)$} \\
\hline Mean & 22.5 & $22 \cdot 9$ & 23.0 & $22 \cdot 8$ \\
\hline SD & $3 \cdot 3$ & $3 \cdot 3$ & $3 \cdot 2$ & $3 \cdot 1$ \\
\hline \multicolumn{5}{|l|}{ Daily activity $(\mathrm{MET} \cdot \mathrm{h} / \mathrm{d})^{*}$} \\
\hline Median & 19.5 & $19 \cdot 9$ & 20.5 & 21.9 \\
\hline 25th-75th percentile & $15 \cdot 8-26 \cdot 1$ & $16 \cdot 0-28 \cdot 3$ & $16 \cdot 4-29 \cdot 3$ & $17 \cdot 7-29 \cdot 0$ \\
\hline \multicolumn{5}{|l|}{ Education level (\%) } \\
\hline Primary school or below & 26.9 & $17 \cdot 1$ & 22.5 & $13 \cdot 8$ \\
\hline Secondary school & $58 \cdot 3$ & $62 \cdot 4$ & $58 \cdot 2$ & $60 \cdot 7$ \\
\hline Collage or higher & 14.9 & 20.4 & $19 \cdot 3$ & 25.5 \\
\hline \multicolumn{5}{|l|}{ Per capita household income level (\%) } \\
\hline$<¥ 2000 /$ month & $44 \cdot 0$ & $32 \cdot 0$ & 35.5 & $35 \cdot 6$ \\
\hline$¥ 2000-4000 /$ month & $35 \cdot 8$ & 44.1 & $40 \cdot 4$ & $36 \cdot 8$ \\
\hline$\geq ¥ 4000 /$ month & $20 \cdot 2$ & 23.9 & $24 \cdot 1$ & 27.5 \\
\hline Urban (\%) & $65 \cdot 8$ & $68 \cdot 0$ & $73 \cdot 1$ & $75 \cdot 3$ \\
\hline Out-of-pocket health payments (\%) & $75 \cdot 7$ & $72 \cdot 9$ & 73.5 & $73 \cdot 3$ \\
\hline AFP > 400 ng/ml (\%) & 58.8 & 61.5 & $63 \cdot 3$ & $60 \cdot 0$ \\
\hline HBsAg (+)/anti-HCV (+) (\%) & 88.9 & 91.5 & $92 \cdot 7$ & $90 \cdot 7$ \\
\hline \multicolumn{5}{|l|}{ Smoking (\%) } \\
\hline Never smoker & $32 \cdot 1$ & 41.3 & 44.9 & $52 \cdot 6$ \\
\hline Former smoker & $31 \cdot 7$ & $26 \cdot 3$ & $26 \cdot 9$ & $23 \cdot 1$ \\
\hline Current smoker & $36 \cdot 2$ & 32.4 & $28 \cdot 2$ & $24 \cdot 3$ \\
\hline \multicolumn{5}{|l|}{ Alcohol drinking (\%) } \\
\hline Never drinker & $54 \cdot 7$ & 61.5 & $58 \cdot 8$ & 59.1 \\
\hline Former drinker & $19 \cdot 3$ & $17 \cdot 8$ & $12 \cdot 7$ & 11.3 \\
\hline Current drinker & $25 \cdot 9$ & $20 \cdot 6$ & $28 \cdot 6$ & $29 \cdot 6$ \\
\hline \multicolumn{5}{|l|}{ Multivitamin use $\dagger$} \\
\hline$n$ & 7 & 3 & 13 & 11 \\
\hline$\%$ & $4 \cdot 3$ & $1 \cdot 7$ & 7.5 & $5 \cdot 6$ \\
\hline \multicolumn{5}{|l|}{ Energy intake $(\mathrm{kcal} / \mathrm{d}) \ddagger$} \\
\hline Mean & 1931 & 2075 & 2031 & 1973 \\
\hline SD & 552 & 623 & 605 & 569 \\
\hline \multicolumn{5}{|l|}{ Dietary folate intake $(\mu \mathrm{g} / \mathrm{d}) \ddagger \S$} \\
\hline Mean & 184.0 & $198 \cdot 7$ & $202 \cdot 1$ & $205 \cdot 2$ \\
\hline SD & 71.9 & 79.9 & $82 \cdot 9$ & $82 \cdot 0$ \\
\hline Alanine aminotransferase (U/l) & & & & \\
\hline Median & $39 \cdot 3$ & $37 \cdot 0$ & 40.9 & 41.5 \\
\hline 25th-75th percentile & $27 \cdot 0-55 \cdot 8$ & $24 \cdot 7-57 \cdot 1$ & $27 \cdot 8-60 \cdot 5$ & $27 \cdot 0-64 \cdot 6$ \\
\hline Aspartate aminotransferase (U/I) & & & & \\
\hline Median & $43 \cdot 1$ & 39.4 & 38.0 & $40 \cdot 6$ \\
\hline 25th-75th percentile & $29 \cdot 0-66 \cdot 0$ & $26 \cdot 2-66 \cdot 7$ & $28 \cdot 3-60 \cdot 0$ & $28 \cdot 9-67.5$ \\
\hline$\gamma$-Glutamyltransferase $(\mathrm{U} / \mathrm{l})$ & & & & \\
\hline Median & 111.1 & $70 \cdot 9$ & $69 \cdot 0$ & 64.7 \\
\hline 25 th-75th percentile & $49.9-206.6$ & $40 \cdot 9-138.0$ & $39.5-120 \cdot 7$ & $36 \cdot 0-128 \cdot 2$ \\
\hline Alkaline phosphatase (U/l) & & & & \\
\hline Median & $113 \cdot 0$ & $100 \cdot 0$ & $95 \cdot 0$ & $90 \cdot 7$ \\
\hline 25th-75th percentile & $84 \cdot 3-157 \cdot 3$ & $78 \cdot 2-126 \cdot 4$ & $77 \cdot 6-122 \cdot 0$ & $71 \cdot 8-125 \cdot 0$ \\
\hline Albumin $(\mathrm{g} / \mathrm{l})$ & & & & \\
\hline Median & $41 \cdot 0$ & $42 \cdot 5$ & 43.0 & $42 \cdot 9$ \\
\hline 25th-75th percentile & $37 \cdot 6-44.0$ & $39 \cdot 5-45 \cdot 0$ & $41 \cdot 0-45 \cdot 2$ & $40 \cdot 0-45 \cdot 2$ \\
\hline Total bilirubin (mmol/l) & & & & \\
\hline Median & $13 \cdot 6$ & $14 \cdot 0$ & 14.0 & $14 \cdot 3$ \\
\hline 25th-75th percentile & $10 \cdot 0-17.9$ & $10 \cdot 5-20 \cdot 1$ & $10 \cdot 1-18 \cdot 6$ & $11 \cdot 1-19 \cdot 0$ \\
\hline Baseline liver damage score (\%)\| & & & & \\
\hline 0 & $16 \cdot 9$ & $25 \cdot 1$ & $22 \cdot 0$ & $23 \cdot 2$ \\
\hline $1-2$ & 33.9 & $35 \cdot 6$ & $46 \cdot 9$ & $39 \cdot 0$ \\
\hline$\geq 3$ & $49 \cdot 2$ & $39 \cdot 3$ & 31.0 & 37.8 \\
\hline Family history of PLC (\%) & $13 \cdot 2$ & 11.3 & $16 \cdot 3$ & $13 \cdot 0$ \\
\hline
\end{tabular}


Table 1. (Continued)

\begin{tabular}{|c|c|c|c|c|}
\hline & \multicolumn{4}{|c|}{ Sex-specific quartile of serum folate } \\
\hline & Q1 (n 243) & Q2 ( $n$ 247) & Q3 (n 245) & Q4 (n 247) \\
\hline Fatty liver disease (\%) & $10 \cdot 7$ & 14.6 & $18 \cdot 8$ & 23.9 \\
\hline Cirrhosis (\%) & $62 \cdot 1$ & $61 \cdot 1$ & 66.5 & 68.4 \\
\hline Diabetes mellitus (\%) & $6 \cdot 2$ & 8.5 & $9 \cdot 0$ & $13 \cdot 8$ \\
\hline CRP > $3.0 \mathrm{mg} / \mathrm{l}(\%)$ & $59 \cdot 8$ & $45 \cdot 3$ & $39 \cdot 6$ & 39.4 \\
\hline \multicolumn{5}{|l|}{ Child-Pugh score (\%) } \\
\hline A & $96 \cdot 7$ & 98.4 & $99 \cdot 2$ & 98.4 \\
\hline B & $3 \cdot 3$ & 1.6 & 0.8 & 1.6 \\
\hline \multicolumn{5}{|l|}{ BCLC stage (\%) } \\
\hline 0 & 8.6 & 8.9 & 11.8 & $15 \cdot 8$ \\
\hline A & $24 \cdot 3$ & $33 \cdot 2$ & $35 \cdot 5$ & 33.2 \\
\hline B & $12 \cdot 3$ & $10 \cdot 1$ & 13.5 & $10 \cdot 1$ \\
\hline $\mathrm{C}$ & 54.7 & $47 \cdot 8$ & $39 \cdot 2$ & $40 \cdot 9$ \\
\hline \multicolumn{5}{|l|}{ Cancer treatment (\%) } \\
\hline Hepatectomy/liver transplantation & 33.7 & $42 \cdot 9$ & 55.5 & $46 \cdot 2$ \\
\hline Local ablation & 9.9 & $11 \cdot 7$ & $9 \cdot 0$ & $14 \cdot 2$ \\
\hline Hepatic arterial intervention & $49 \cdot 8$ & 41.3 & $32 \cdot 2$ & 34.8 \\
\hline Other treatments & $6 \cdot 6$ & 4.0 & $3 \cdot 3$ & 4.9 \\
\hline
\end{tabular}

MET, metabolic equivalent; AFP, $\alpha$-fetoprotein; HBsAg, hepatitis B surface antigen; anti-HCV, hepatitis C antibody; PLC, primary liver cancer; CRP, C-reactive protein; BCLC, Barcelona Clinic Liver Cancer.

*Including work, transportation, housework, physical exercises and leisure sedentary activity.

† Data were available for 709 patients.

‡ Dietary data were available for 674 patients. To convert energy in $\mathrm{kcal} / \mathrm{d}$ to $\mathrm{kJ} / \mathrm{d}$, multiply by $4 \cdot 184$. To convert folate in $\mu \mathrm{g} / \mathrm{d}$ to $\mathrm{nmol} / \mathrm{l}, \mathrm{multiply}$ by $2 \cdot 27$.

$\S$ Dietary folate intake was standardised to $2000 \mathrm{kcal}(8368 \mathrm{~kJ})$ using the residual method.

II A summary score of the number of abnormal laboratory-defined values for six liver function tests: alanine aminotransferase $>50 \mathrm{U} / \mathrm{l}$, aspartate aminotransferase $>40 \mathrm{U} / \mathrm{l}, \gamma$-glutaryl-transferase $>60 \mathrm{U} / \mathrm{l}$, alkaline phosphatase $>150 \mathrm{U} / \mathrm{l}$, albumin $<40 \mathrm{~g} / \mathrm{l}$ and total bilirubin $>20.5 \mu \mathrm{mol} / \mathrm{l}$, ranging from 0 to 6 .

If Including radiation therapy and systemic treatment (e.g. molecular targeted therapy, systemic chemotherapy, traditional Chinese medication).

Table 2. Multivariable-adjusted associations between sex-specific quartiles $(Q)$ of serum folate concentrations and survival outcomes in the Guangdong Liver Cancer Cohort study

(Mortality rates, hazard ratios (HR) and $95 \%$ confidence intervals)

\begin{tabular}{|c|c|c|c|c|c|c|c|c|c|}
\hline & \multicolumn{9}{|c|}{ Sex-specific quartile of serum folate* } \\
\hline & \multicolumn{2}{|c|}{ Q1 (n 243) } & \multicolumn{2}{|c|}{ Q2 (n 247) } & \multicolumn{2}{|c|}{ Q3 (n 245) } & \multicolumn{2}{|c|}{ Q4 (n 247) } & \multirow[b]{2}{*}{$P$ trend§ } \\
\hline & $\mathrm{HR}$ & $95 \% \mathrm{Cl}$ & $\mathrm{HR}$ & $95 \% \mathrm{Cl}$ & $\mathrm{HR}$ & $95 \% \mathrm{Cl}$ & $\mathrm{HR}$ & $95 \% \mathrm{Cl}$ & \\
\hline \multicolumn{10}{|l|}{ Liver cancer-specific survival } \\
\hline Number of deaths & \multirow{2}{*}{\multicolumn{2}{|c|}{$\begin{array}{c}94 \\
106457\end{array}$}} & \multirow{2}{*}{\multicolumn{2}{|c|}{$\begin{array}{c}65 \\
121392\end{array}$}} & \multirow{2}{*}{\multicolumn{2}{|c|}{$\begin{array}{c}56 \\
143425\end{array}$}} & \multirow{2}{*}{\multicolumn{2}{|c|}{$\begin{array}{c}77 \\
160653\end{array}$}} & - \\
\hline Person-days at risk & & & & & & & & & - \\
\hline Mortality rate per 10000 person-days & 8.83 & $7 \cdot 04,10 \cdot 61$ & $5 \cdot 35$ & $4.05,6.66$ & 3.90 & $2.88,4.93$ & 4.79 & $3 \cdot 72,5 \cdot 86$ & - \\
\hline Adjusted HR $\dagger$ & 2.08 & $1.49,2.90$ & 1.31 & $0.92,1.88$ & 1 & (Reference) & 1.26 & $0.89,1.78$ & $<0.01$ \\
\hline Fully adjusted HR $\ddagger$ & 1.48 & $1.05,2.09$ & 1.21 & $0.84,1.74$ & 1 & (Reference) & 1.17 & $0.82,1.66$ & 0.08 \\
\hline \multicolumn{10}{|l|}{ Overall survival } \\
\hline Number of deaths & \multirow{2}{*}{\multicolumn{2}{|c|}{$\begin{array}{c}100 \\
106457\end{array}$}} & \multirow{2}{*}{\multicolumn{2}{|c|}{$\begin{array}{c}72 \\
121392\end{array}$}} & \multirow{2}{*}{\multicolumn{2}{|c|}{$\begin{array}{c}62 \\
143425\end{array}$}} & \multirow{2}{*}{\multicolumn{2}{|c|}{$\begin{array}{c}85 \\
160653\end{array}$}} & - \\
\hline Person-days at risk & & & & & & & & & - \\
\hline Mortality rate per 10000 person-days & $9 \cdot 39$ & $7.55,11.23$ & 5.93 & $4 \cdot 56,7 \cdot 30$ & $4 \cdot 32$ & $3 \cdot 25,5 \cdot 40$ & $5 \cdot 29$ & $4 \cdot 17,6 \cdot 42$ & - \\
\hline Adjusted HR $\dagger$ & 2.01 & $1.46,2 \cdot 76$ & 1.32 & $0.94,1.85$ & 1 & (Reference) & 1.25 & $0.90,1.74$ & $<0.01$ \\
\hline Fully adjusted HR $\ddagger$ & 1.43 & $1.03,1.99$ & 1.20 & $0.85,1.69$ & 1 & (Reference) & $1 \cdot 15$ & $0.83,1.61$ & $0 \cdot 10$ \\
\hline
\end{tabular}

BCLC, Barcelona Clinic Liver Cancer.

* Sex-specific quartile ranges of serum folate are: women: Q1=2.64-6.91 ng/ml, Q2 = 6.92-9.30 ng $/ \mathrm{ml}, \mathrm{Q} 3=9 \cdot 31-11 \cdot 18 \mathrm{ng} / \mathrm{ml}, \mathrm{Q} 4=11 \cdot 19-19 \cdot 51 \mathrm{ng} / \mathrm{ml}$; $\mathrm{men}: \mathrm{Q} 1=1 \cdot 63-5 \cdot 19 \mathrm{ng} / \mathrm{ml}$, $\mathrm{Q} 2=5.20-6.87 \mathrm{ng} / \mathrm{ml}, \mathrm{Q} 3=6.88-9.14 \mathrm{ng} / \mathrm{ml}, \mathrm{Q} 4=9.15-19.74 \mathrm{ng} / \mathrm{ml}$.

$\dagger$ Adjusted for age at diagnosis (continuous), sex (women, men), BMI (continuous), smoking status (never, former, current) and alcohol drinking status (never, former, current). $\ddagger$ Additionally adjusted for C-reactive protein level $(\leq 3.0 \mathrm{mg} / \mathrm{l},>3.0 \mathrm{mg} / \mathrm{l})$, baseline liver damage score $(0,1-2, \geq 3), B C L C$ stage $(0, A, B, C)$ and cancer treatment $($ hepatectomy/liver transplantation, local ablation, hepatic arterial intervention, other treatments).

$\S$ The quartiles are treated as an ordered value in the models.

However, there were statistically significant interactions on both multiplicative and additive scales between serum folate and systemic inflammation or smoking status, and the associations of lower serum folate with worse LCSS and OS were only evident among patients with systemic inflammation or current smokers. An inverse association between serum folate and LCSS was also observed among patients with preexisting liver damage, but the interaction testing with liver damage score was not statistically significant.
Numerous epidemiological studies have examined the association between folate status and cancer mortality or survival. Mortality data from 28845 participants included in the US National Health and Nutrition Examination Survey during 1999-2010 showed that the risk of cancer mortality decreased gradually with serum folate concentrations reaching a threshold at approximately $40 \mathrm{nmol} / \mathrm{l}$, suggesting that lower serum folate concentrations, but not restricted to folate deficiency, are associated with an increase in cancer mortality ${ }^{(18)}$. Rossi et al. ${ }^{(19)}$ 
Table 3. Multivariable-adjusted associations between sex-specific quartiles $(Q)^{*}$ of serum folate concentrations and survival outcomes stratified by possible effect modifiers in the Guangdong Liver Cancer Cohort study

(Hazard ratios (HR) and $95 \%$ confidence intervals)

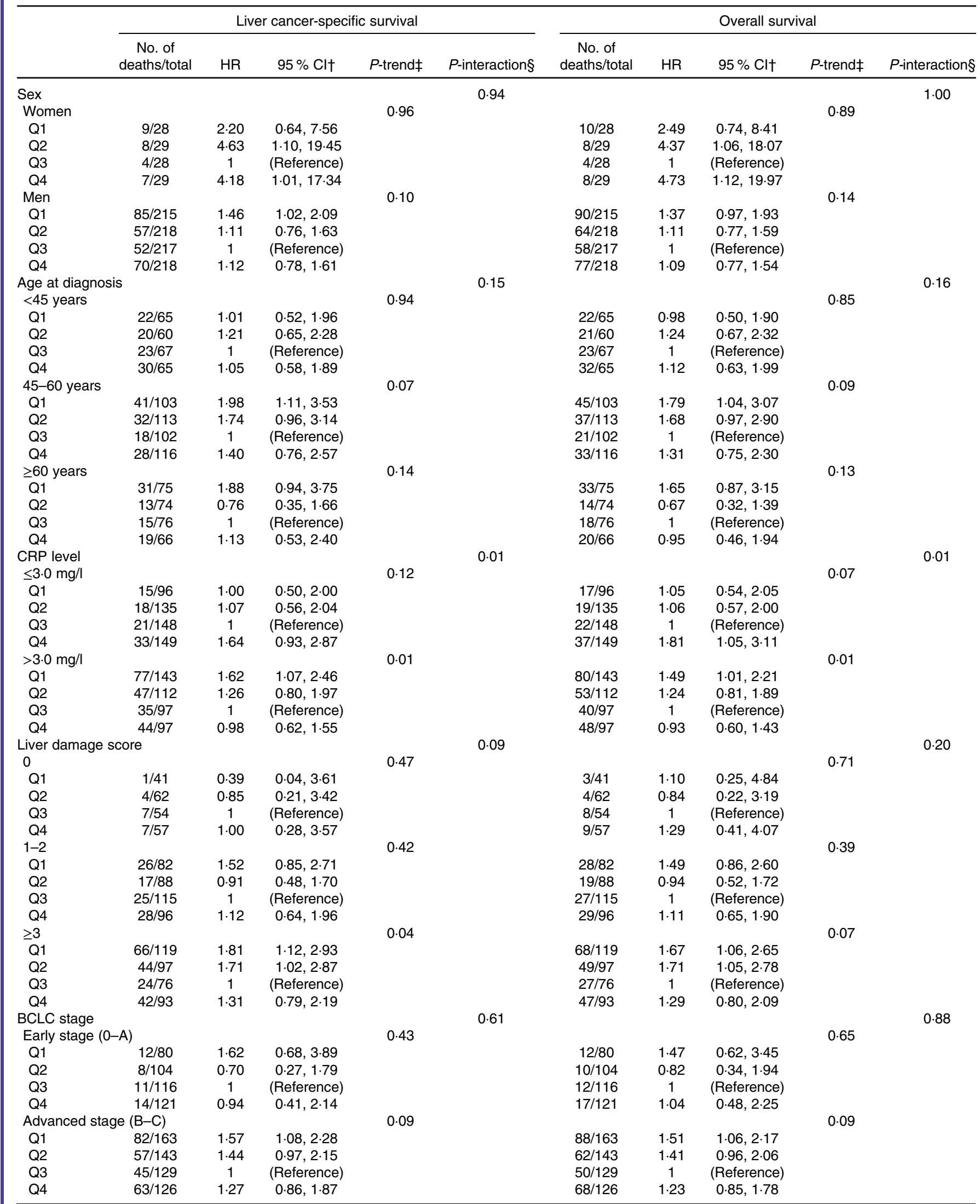


Table 3. (Continued)

\begin{tabular}{|c|c|c|c|c|c|c|c|c|c|c|}
\hline & \multicolumn{5}{|c|}{ Liver cancer-specific survival } & \multicolumn{5}{|c|}{ Overall survival } \\
\hline & $\begin{array}{c}\text { No. of } \\
\text { deaths/total }\end{array}$ & HR & $95 \% \mathrm{Cl} \dagger$ & $P$-trend $\ddagger$ & $P$-interaction§ & $\begin{array}{c}\text { No. of } \\
\text { deaths/total }\end{array}$ & $\mathrm{HR}$ & $95 \% \mathrm{Cl} \dagger$ & $P$-trend $\ddagger$ & $P$-interaction $\S$ \\
\hline Smoking & & & & & 0.01 & & & & & $<0.01$ \\
\hline Never smoker & & & & 0.67 & & & & & 0.44 & \\
\hline Q1 & $21 / 78$ & $1 \cdot 15$ & $0.62,2 \cdot 12$ & & & $22 / 78$ & $1 \cdot 17$ & $0 \cdot 64,2 \cdot 14$ & & \\
\hline Q2 & $25 / 102$ & 1.32 & $0.75,2.31$ & & & $25 / 102$ & 1.25 & $0.72,2.18$ & & \\
\hline Q3 & $25 / 110$ & 1 & (Reference) & & & $26 / 110$ & 1 & (Reference) & & \\
\hline Q4 & $37 / 130$ & 1.38 & $0.82,2.33$ & & & $41 / 130$ & 1.49 & $0.90,2.48$ & & \\
\hline Former smoker & & & & 0.17 & & & & & 0.25 & \\
\hline Q1 & $34 / 77$ & 1.02 & $0.56,1.87$ & & & $35 / 77$ & 0.87 & $0.49,1.54$ & & \\
\hline Q2 & $22 / 65$ & 0.78 & $0.40,1.51$ & & & $25 / 65$ & 0.74 & $0.40,1.38$ & & \\
\hline Q3 & $21 / 66$ & 1 & (Reference) & & & $25 / 66$ & 1 & (Reference) & & \\
\hline Q4 & $17 / 57$ & 0.58 & $0.29,1.17$ & & & $20 / 57$ & 0.53 & $0.28,1.02$ & & \\
\hline Current smoker & & & & $<0.01$ & & & & & $<0.01$ & \\
\hline Q1 & $39 / 88$ & 4.98 & $2 \cdot 29,10 \cdot 84$ & & & $43 / 88$ & 4.59 & $2 \cdot 19,9 \cdot 63$ & & \\
\hline Q2 & $18 / 80$ & $2 \cdot 71$ & $1 \cdot 17,6 \cdot 32$ & & & $22 / 80$ & $2 \cdot 79$ & $1 \cdot 27,6 \cdot 14$ & & \\
\hline Q3 & $10 / 69$ & 1 & (Reference) & & & $11 / 69$ & 1 & (Reference) & & \\
\hline Q4 & $23 / 60$ & 2.08 & $0.95,4.57$ & & & $24 / 60$ & 1.93 & $0.91,4.09$ & & \\
\hline Alcohol drinking & & & & & 0.51 & & & & & 0.34 \\
\hline Never drinker & & & & 0.15 & & & & & 0.26 & \\
\hline Q1 & $50 / 133$ & 1.65 & $1 \cdot 01,2 \cdot 68$ & & & $53 / 133$ & 1.55 & $0.97,2.48$ & & \\
\hline Q2 & $42 / 152$ & 1.58 & $0.97,2.57$ & & & $46 / 152$ & 1.56 & $0.98,2.49$ & & \\
\hline Q3 & $28 / 144$ & 1 & (Reference) & & & $31 / 144$ & 1 & (Reference) & & \\
\hline Q4 & $47 / 146$ & 1.32 & $0.82,2.13$ & & & $53 / 146$ & 1.35 & $0.86,2.13$ & & \\
\hline Former drinker & & & & 0.06 & & & & & 0.05 & \\
\hline Q1 & $17 / 47$ & 0.36 & $0.14,0.94$ & & & $18 / 47$ & 0.34 & $0.13,0.86$ & & \\
\hline Q2 & $7 / 44$ & 0.19 & $0.06,0.62$ & & & $7 / 44$ & 0.17 & $0.05,0.53$ & & \\
\hline Q3 & $9 / 31$ & 1 & (Reference) & & & $10 / 31$ & 1 & (Reference) & & \\
\hline Q4 & $10 / 28$ & 0.79 & $0.27,2.30$ & & & $11 / 28$ & 0.75 & $0.27,2.11$ & & \\
\hline Current drinker & & & & 0.04 & & & & & 0.04 & \\
\hline Q1 & $27 / 63$ & 2.59 & $1 \cdot 37,4 \cdot 89$ & & & $29 / 63$ & $2 \cdot 36$ & $1 \cdot 28,4 \cdot 34$ & & \\
\hline Q2 & $16 / 51$ & 1.29 & $0.65,2.58$ & & & $19 / 51$ & 1.38 & $0.72,2.63$ & & \\
\hline Q3 & $19 / 70$ & 1 & (Reference) & & & $21 / 70$ & 1 & (Reference) & & \\
\hline Q4 & $20 / 73$ & 1.49 & $0.77,2.90$ & & & $21 / 73$ & 1.38 & $0.73,2.61$ & & \\
\hline
\end{tabular}

CRP, C-reactive protein; BCLC, Barcelona Clinic Liver Cancer.

*Sex-specific quartile ranges of serum folate are: women: Q1=2.64-6.91 ng/ml, Q2=6.92-9.30 ng/ml, Q3=9.31-11.18 ng/ml, Q4=11.19-19.51 ng/ml; men: Q1=1.63-5.19 ng/ml, $\mathrm{Q} 2=5 \cdot 20-6.87 \mathrm{ng} / \mathrm{ml}, \mathrm{Q} 3=6 \cdot 88-9.14 \mathrm{ng} / \mathrm{ml}, \mathrm{Q} 4=9 \cdot 15-19.74 \mathrm{ng} / \mathrm{ml}$.

† Adjusted for age at diagnosis (continuous), sex (women, men), BMI (continuous), smoking status (never, former, current), alcohol drinking status (never, former, current), CRP level $(\leq 3.0 \mathrm{mg} / \mathrm{l},>3.0 \mathrm{mg} / \mathrm{l})$, baseline liver damage score $(0,1-2, \geq 3)$, BCLC stage $(0, \mathrm{~A}, \mathrm{~B}, \mathrm{C})$ and cancer treatment (hepatectomy/liver transplantation, local ablation, hepatic arterial intervention, other treatments), and the corresponding variable was removed from the multivariable models when it was a stratified factor.

¥ The quartiles were treated as an ordered value in the models.

$\S$ Interactions were assessed using likelihood ratio tests based on the models with and without the interaction terms.

followed 1988 men and women who participated in the 1969 Busselton Health Survey for over 29 years and observed that participants with folate deficiency $(<3.00 \mathrm{ng} / \mathrm{ml})$ at baseline were at increased risk of dying from prostate cancer, but not from breast, colorectal and lung cancers, in comparison with those with sufficient folate levels $(\geq 6.00 \mathrm{ng} / \mathrm{ml}$ ). In line with the study by Rossi et al. ${ }^{(19)}$, a case-control study nested within the Japan Collaborative Cohort Study also show no association of serum folic acid concentrations (geometric mean: $5.21 v .5 .46 \mathrm{ng} / \mathrm{ml}$ in men and $6.21 v .6 .63 \mathrm{ng} / \mathrm{ml}$ in women for cases $v$. controls) with the risk of lung cancer death ${ }^{(38)}$. In contrast, results from the Nurses' Health Study and Health Professionals Follow-Up Study indicated that higher concentrations of prediagnostic plasma folate were related to superior colorectal cancer-specific survival and OS among 301 participants who developed colorectal cancer during follow-up with a median folate concentration of $6.9 \mathrm{ng} / \mathrm{ml}^{(20)}$, whereas no similar associations were observed between total folate intake (from food and supplemental sources) after diagnosis and colorectal cancer-specific and overall mortality among 1550 stage I-III colorectal cancer patients consuming 978 dietary folate equivalents daily on average $^{(39)}$. McEligot et $a l .^{(21)}$ reported an inverse association between plasma total folate concentrations and OS after breast cancer diagnosis during an average follow-up of 6.7 years among 471 postmenopausal women (mean folate concentration: $29.9 \mathrm{nmol} / \mathrm{l})$. Likewise, compared with patients in the lowest quartile of dietary folate intake $(<190 \mu \mathrm{g} / \mathrm{d})$, patients in the highest quartile $(\geq 246 \mu \mathrm{g} / \mathrm{d})$ had significantly improved breast cancer-specific survival and OS among 3116 women who developed breast cancer according to the findings from the Swedish Mammography Cohort Study ${ }^{(40)}$. With reference to gastric cancer, a serum folate concentration $<1.90 \mathrm{ng} / \mathrm{ml}$ has been linked with poor survival in 155 patients $^{(41)}$, and higher dietary folate intakes have been suggested to be associated with reduced risk of gastric cancer mortality among susceptible MTHFR 677TT carriers ${ }^{(42)}$. However, a follow-up study of 548 participants with incident renal cell carcinoma from the European Prospective Investigation into Cancer and Nutrition Study failed to show any association between plasma folate concentrations (median: $11.86 \mathrm{nmol} / \mathrm{l}$ ) and all-cause mortality ${ }^{(43)}$. Similarly, a prospective 
(a)

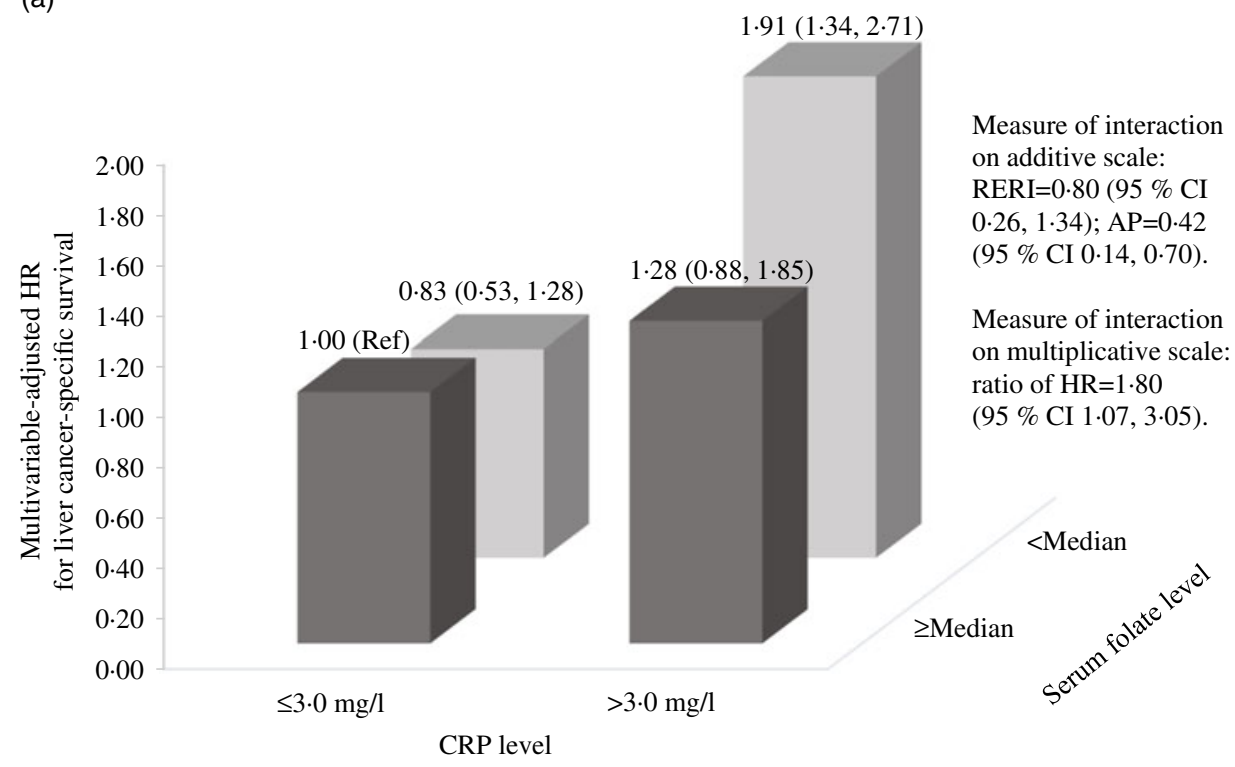

(b)

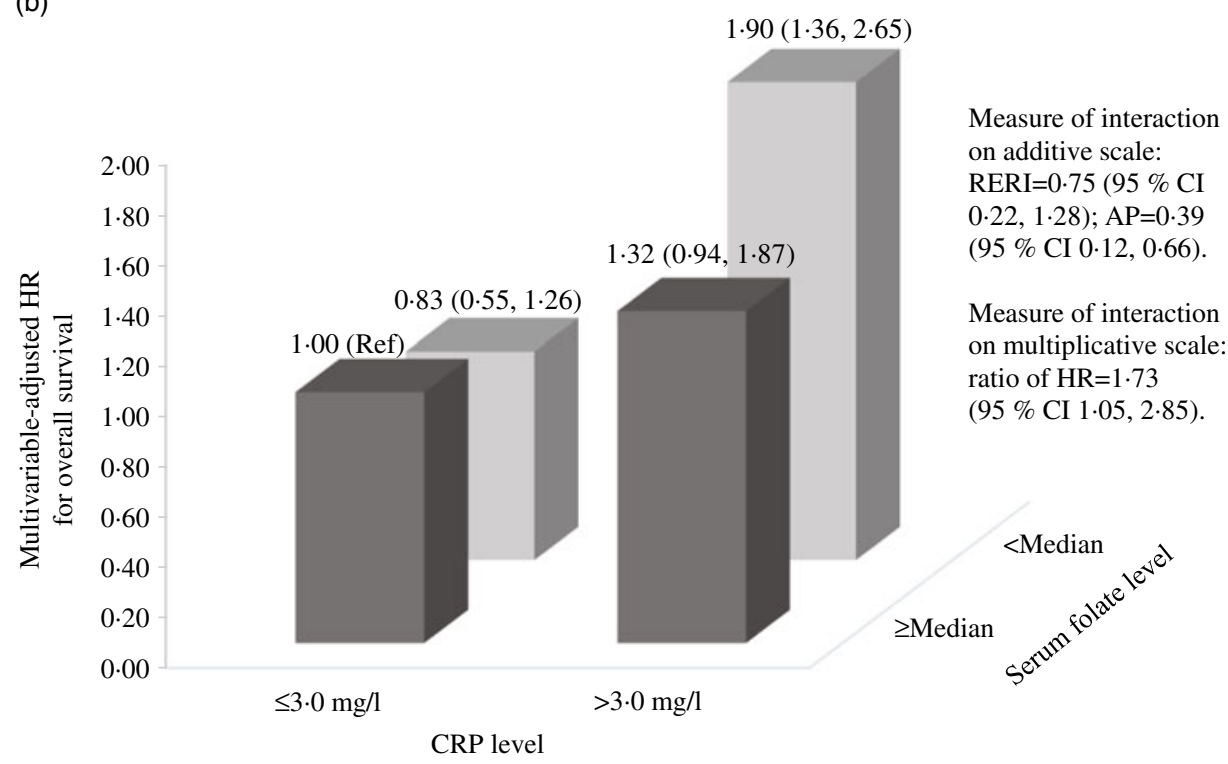

Fig. 2. Joint effects of serum folate and C-reactive protein (CRP) levels on survival outcomes in the Guangdong Liver Cancer Cohort study. (a) Liver cancer-specific survival and (b) overall survival. HR, hazard ratio; Ref, reference; RERI, relative excess risk due to interaction; AP, attributable proportion due to interaction. Measures for additive interaction and corresponding $95 \% \mathrm{Cl}$ are estimated using the delta method. HR are estimated from Cox proportional hazards models adjusting for age at diagnosis (continuous), sex (women, men), BMI (continuous), smoking status (never, former, current), alcohol drinking status (never, former, current), baseline liver damage score $(0,1-2, \geq 3)$, Barcelona Clinic Liver Cancer stage $(0, A, B, C)$ and cancer treatment (hepatectomy/liver transplantation, local ablation, hepatic arterial intervention, other treatments).

cohort study of 1270 women with invasive epithelial ovarian cancer also found little evidence that total folate intake (mean: $481 \mu \mathrm{g} / \mathrm{d}$ ) was linked with ovarian cancer survival ${ }^{(44)}$. Although results from the Norwegian Vitamin Trial and Western Norway B Vitamin Intervention Trial have raised the concern about the role of treatment with folic acid plus vitamin $\mathrm{B}_{12}$ in increasing cancer mortality ${ }^{(45)}$, none of the aforementioned studies has observed a positive association of circulating folate concentration or dietary folate intake with overall or site-specific cancer mortality/survival. The inconsistent findings of the previous studies are likely due to the difference in the timing (before/after diagnosis), dose (dietary folate intake/circulating folate concentration) and cancer type ${ }^{(46,47)}$. Most of the previous studies have measured circulating folate concentrations prior to cancer diagnosis, and few have assessed postdiagnostic folate status. It should be noted that circulating folate concentrations in the present study are comparable with or even higher than those in the Asian and US cohorts ${ }^{(20,38)}$, in which mandatory folate fortification has not been started at the time of blood sampling (1993-1995 in Nurses' Health Study and 
(a)

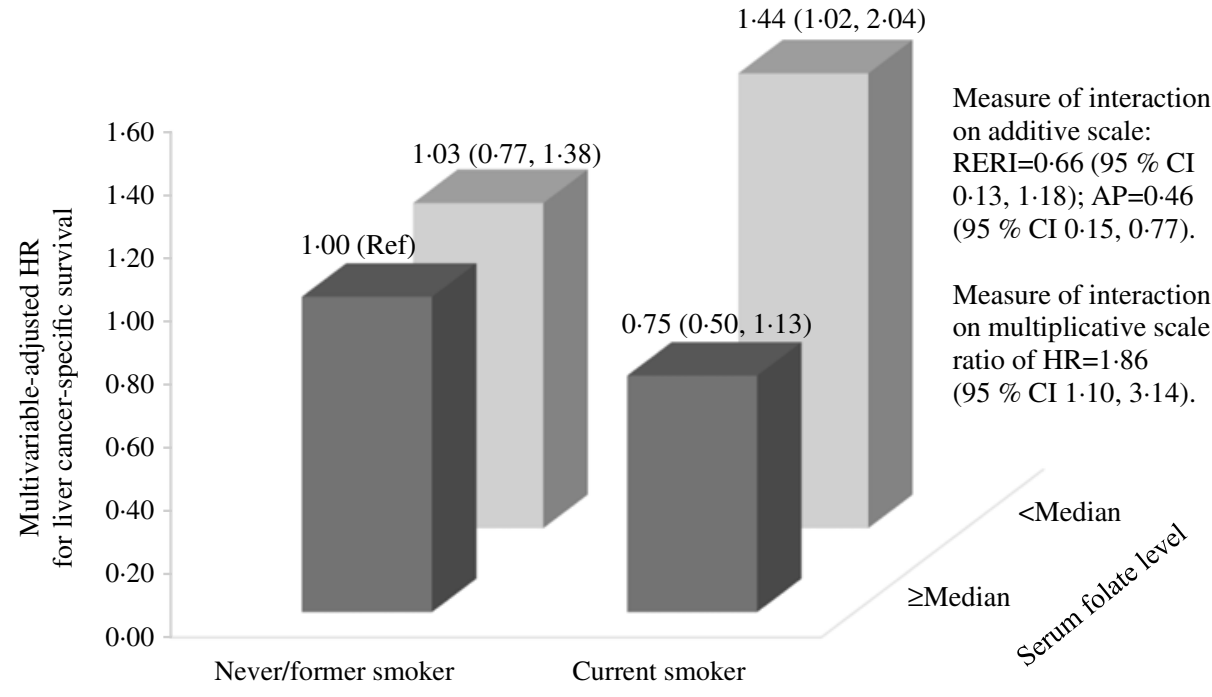

Smoking status

(b)

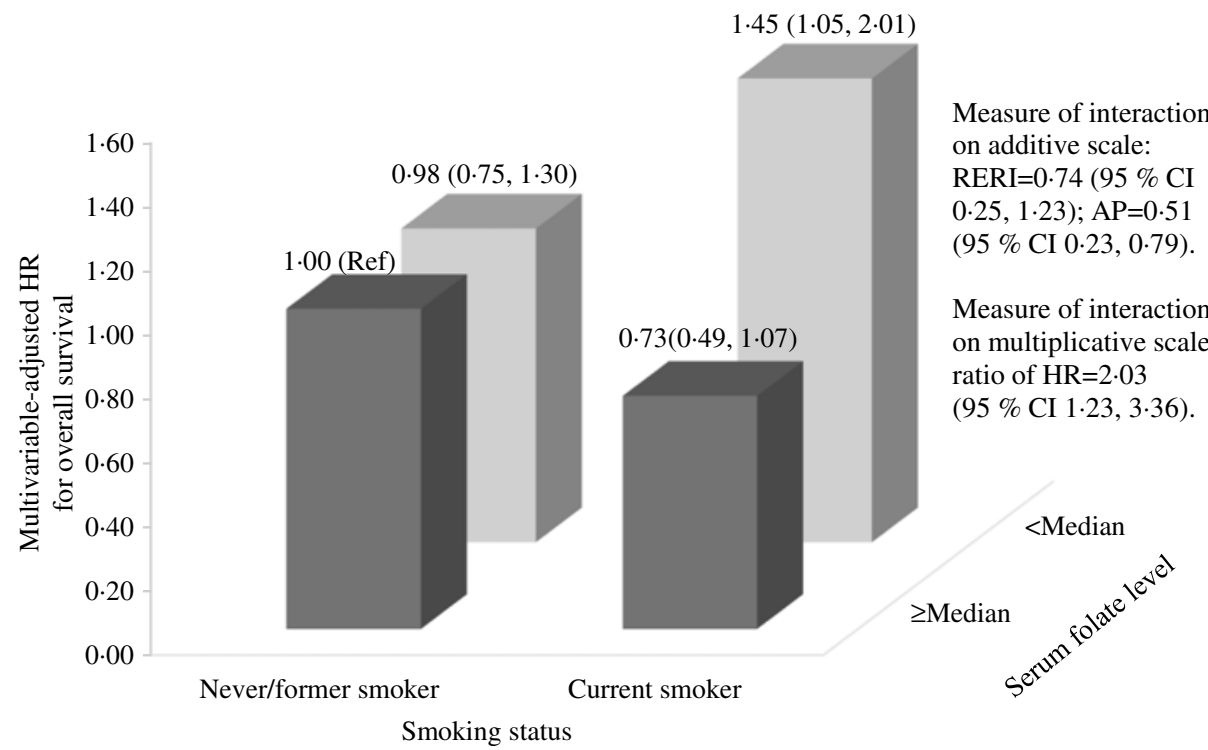

Fig. 3. Joint effects of serum folate and smoking status on survival outcomes in the Guangdong Liver Cancer Cohort study. (a) Liver cancer-specific survival and (b) overall survival. HR, hazard ratio; Ref, reference; RERI, relative excess risk due to interaction; AP, attributable proportion due to interaction. Measures for additive interaction and corresponding $95 \% \mathrm{Cl}$ are estimated using the delta method. HR are estimated from Cox proportional hazards models adjusting for age at diagnosis (continuous), sex (women, men), BMl (continuous), alcohol drinking status (never, former, current), C-reactive protein level ( $\leq 3.0 \mathrm{mgl},>3.0 \mathrm{mg} / \mathrm{l})$, baseline liver damage score $(0,1-2, \geq 3)$, Barcelona Clinic Liver Cancer stage $(0, A, B, C)$ and cancer treatment (hepatectomy/liver transplantation, local ablation, hepatic arterial intervention, other treatments).

Health Professionals Follow-Up Study). Nevertheless, both circulating folate concentrations and total folate intake increased dramatically in American populations after the implementation of mandatory folate fortification ${ }^{(18,39)}$. Circulating folate concentrations in the European patients with renal cell carcinoma ${ }^{(43)}$ and total folate intake in the Australian patients with ovarian cancer ${ }^{(44)}$ are higher than those in the study population as well, which is possibly due to the widespread use of folic acid-containing supplements in European and Australian populations.
Existing data are scarce on HCC. Yeh et al. ${ }^{(22)}$ prospectively evaluated the association between plasma folate concentrations and OS among 160 HCC patients with a median follow-up of $1 \cdot 12$ years and found that patients with plasma folate $<12.2 \mathrm{ng} / \mathrm{ml}$ had worse survival than those with plasma folate $\geq 12 \cdot 2 \mathrm{ng} / \mathrm{ml}$ ( $\mathrm{HR}=1.96 ; 95 \%$ CI 1.24, 3.09). We add to similar observations in Chinese populations, despite that the study by Yeh et al. was conducted in American populations who had almost twice as much circulating folate concentrations as our study population $(12 \cdot 2 v \cdot 7 \cdot 13 \mathrm{ng} / \mathrm{ml})$ due to mandatory folic acid fortification 
and use of folate-containing supplements ${ }^{(23,48)}$. In our study, patients in the first quartile (range of serum folate: $2 \cdot 64-6.91 \mathrm{ng} / \mathrm{ml}$ for women and $1.63-5.19 \mathrm{ng} / \mathrm{ml}$ for men) had a $48 \%$ higher risk of liver cancer-specific mortality and a $43 \%$ higher risk of all-cause mortality after adjustment for non-clinical and clinical prognostic factors, compared with patients who had serum folate concentrations in the third quartile (range of serum folate: $9 \cdot 31-11.18 \mathrm{ng} / \mathrm{ml}$ for women and $6 \cdot 88-9.14 \mathrm{ng} / \mathrm{ml}$ for men). Notably, folate status of the study population was generally good with a median serum folate concentration of $7 \cdot 13 \mathrm{ng} / \mathrm{ml}$ and only $2 \cdot 2 \%$ of the patients were classified as severe folate deficiency, which may be a consequence of a relatively high dietary folate intake $(197.9 v .180 .9 \mu \mathrm{g} / \mathrm{d})$ and low frequencies of the MTHFR 677TT genotype (7\%; 95\% CI: 5\%, 8\%) and the MTHFR 677 T allele (25\%; 95\% CI: $23 \%, 27 \%)$ in southern Chinese population ${ }^{(49,50)}$. Overall, the study population has comparable serum folate concentrations with participants from other Chinese cohorts (geometric mean 14.7 (95\% CI $11 \cdot 4,19 \cdot 0) \mathrm{nmol} / \mathrm{l})^{(24)}$. These findings indicate that lower circulating folate concentrations, but not restricted to low folate status $(<3 \mathrm{ng} / \mathrm{ml})$, are associated with inferior survival among HCC patients. The associations were largely consistent across different strata of sex, age, alcohol drinking status and BCLC stage. Although alcohol consumption has been linked with folate deficiency and liver disease progression ${ }^{(17,51)}$, alcohol drinking status did not modify the relationship between serum folate and HCC survival in the current study. Similarly, the findings from the NIH-AARP Diet and Health Study also showed no interaction between folate intake and alcohol consumption on the association with liver disease mortality ${ }^{(17)}$. Smoking is another risk factor for both folate deficiency and $\mathrm{HCC}^{(52,53)}$. In the present study, we observed a synergy of lower folate concentrations and current smoking in the prognosis of HCC. Lower folate concentrations were significantly associated with worse HCC survival among current smokers but not among never and former smokers, suggesting that current smokers might benefit most from improving folate status. CRP, a marker of systemic inflammation, has been identified as a prognostic factor for $\mathrm{HCC}^{(54)}$. In the study population, CRP was inversely associated with folate status and when stratified by CRP levels, an inverse association of serum folate concentrations with survival outcomes was pronounced only among HCC patients with systemic inflammation (CRP $>3.0 \mathrm{mg} / \mathrm{l})$. Elevating serum folate concentrations may prolong the survival time of HCC patients with systemic inflammation. In addition, folate status has been reported to be related to liver damage ${ }^{(16)}$. According to our observations, lower folate concentrations were strongly linked with worse LCSS in patients with preexisting liver damage (liver damage score $\geq 3$ ). However, these findings should be interpreted with caution because interaction testing with liver damage score was not significant.

Although it remains obscure how lower folate status exactly contributes to inferior HCC survival, several potential reasons can be considered. Folate, as a methyl donor, is involved in DNA methylation, as well as DNA synthesis and repair ${ }^{(5)}$. Given the crucial role of folate in DNA methylation, inadequate folate would lead to epigenetic changes in human tumours: global DNA hypomethylation and site-specific CpG island promoter hypermethylation ${ }^{(55)}$. Long interspersed nucleotide elements-1 hypomethylation in the plasma and white blood cells, a surrogate marker for global DNA hypomethylation, has been reported to be associated with poor prognosis in HCC patients ${ }^{(22)}$. In addition, folate deficiency can disturb hepatic methionine metabolism, increase DNA strand breaks and promote liver damage ${ }^{(56)}$. Nevertheless, it must be noted that poor survival is not restricted to patients with low-folate status, but even extended to those with marginal folate deficiency.

Another concern is that excess folate may promote cancer progression after the development of neoplastic foci. Rapid tumour cell proliferation requires higher rates of DNA replication, which in turn, needs enough folate and other one-carbon donors for nucleotide synthesis. In animal models of breast cancer, a high dose of folic acid has been reported to enhance tumour growth ${ }^{(7)}$, while withdraw of folate is thought to cause a reduction in growth rate of hepatoma cells ${ }^{(12)}$. A Taiwan study observed that higher erythrocyte folate levels were associated with inferior survival among 232 HCC patients who had a median erythrocyte folate level of $688 \mathrm{ng} / \mathrm{ml}^{(57)}$. Notably, our observations also suggest that patients in the top quartile of serum folate tend to experience an increased risk of liver cancer-specific and overall mortality, although not statistically significant. Nevertheless, erythrocytes and serum folate concentrations are not the same indicators, additional efforts are needed to verify the hypothesis in a broader range of circulating folate concentrations.

Several strengths of this study lend credibility to its findings. First, we prospectively enrolled a homogeneous patient population with first incident HCC and collected blood samples within $30 \mathrm{~d}$ of diagnosis to eliminate potential confounding by receiving anticancer therapy. Second, serum folate concentrations were centrally measured in the same laboratory with strict quality control. Third, we collected detailed covariate information, including demographics, lifestyle, clinical characteristics and cancer treatment, thereby minimising the possibility of residual confounding. Fourth, the sample size is large for an outcome study of this kind. And finally, both OS and LCSS were used as endpoints in our analyses, although HCC is a highly lethal cancer.

We also acknowledge several limitations in our study. We have only one measurement of serum folate made at the time of diagnosis. Changes in diet and lifestyle, cancer progression and tumour-targeting therapy, especially receiving chemotherapy inhibiting the folate circle, may influence circulating folate concentrations following diagnosis. Yet we do not have information on biomarkers of other one-carbon nutrients (e.g. vitamin $\mathrm{B}_{2}$, vitamin $\mathrm{B}_{6}$, vitamin $\mathrm{B}_{12}$, choline and betaine). Additionally, we cannot rule out the possibility of reverse causality, given the fact that serum folate reduced as HCC progressed $^{(13,58,59)}$. However, the inverse associations remained evident after further adjusting for clinical prognostic factors including preexisting liver damage, BCLC stage and cancer treatment. Moreover, both preexisting liver damage and BCLC stage were not significant effect modifiers for the association between serum folate and HCC survival in our study. In addition, we cannot entirely exclude the possibility that excess folate may adversely influence HCC survival since serum folate concentrations in our patients were relatively low and within a narrow range. Lastly, caution should be taken when generalisation of 
the conclusion to racially diverse patient populations since all our study participants are of Asian descent.

\section{Conclusions}

In summary, the findings from this prospective cohort study suggest that lower serum folate concentrations at diagnosis, but not restricted to severe folate deficiency, are associated with worse survival in HCC patients, especially in those with systemic inflammation and current smokers. Given that both food fortification and supplement use are not yet popular in China, a future trial of folate supplementation seems to be promising in HCC patients with lower folate status.

\section{Supplementary material}

To view supplementary material for this article, please visit https://doi.org/10.1017/S0007114519000734

\section{Acknowledgments}

The authors thank the office and field staff of SYSUCC for data collection, processing and preparation. We thank all GLCC study participants for their contributions to this study.

This work was supported by the National Natural Science Foundation of China (A. P. F., grant number 81803219; H. L. Z., grant number 81472966); the Medical Research Foundation of Guangdong Province, China (A. P. F., grant number A2018402); the Natural Science Foundation of Guangdong Province, China (A. P. F., grant number 2018A030310335) and the Fundamental Research Funds for the Central Universities, China (A. P. F., grant number 17ykpy14). The funders had no role in the design, analysis or writing of this article.

A. P. F., M. S. C., Y. J. Z. and H. L. Z. designed the research; A. P. F., Z. Y. L., G. C. L., P. Y. C., X. Y. W., D. M. Z., Y. L., J. A. L., R. H. Z., Z. G. Z., Y. J. X., X. J. X., W. H. L., M. S. C., Y. J. Z. and H. L. Z. conducted the research; Z. G. Z., Y. J. X., X. J. X., M. S. C. and Y. J. Z. provided the essential materials; A. P. F. analysed the data; A. F. P. wrote and revised the paper; A. P. F., Y. J. Z. and H. L. Z. had primary responsibility for the final content. All authors read and approved the final manuscript.

There were no conflicts of interest.

\section{References}

1. Torre LA, Bray F, Siegel RL, et al. (2015) Global cancer statistics, 2012. CA Cancer J Clin 65, 87-108.

2. Allemani C, Matsuda T, Di Carlo V, et al. (2018) Global surveillance of trends in cancer survival 2000-14 (CONCORD-3): analysis of individual records for 37513025 patients diagnosed with one of 18 cancers from 322 population-based registries in 71 countries. Lancet 391, 1023-1075.

3. Llovet JM, Zucman-Rossi J, Pikarsky E, et al. (2016) Hepatocellular carcinoma. Nat Rev Dis Primers 2, 16018.

4. Bruix J, Sherman M, Llovet JM, et al. (2001) Clinical management of hepatocellular carcinoma. Conclusions of the Barcelona-2000 EASL Conference. European Association for the Study of the Liver. J Hepatol 35, 421-430.
5. Newman AC \& Maddocks ODK (2017) One-carbon metabolism in cancer. Br J Cancer 116, 1499-1504.

6. Lamprecht SA \& Lipkin M (2003) Chemoprevention of colon cancer by calcium, vitamin D and folate: molecular mechanisms. Nat Rev Cancer 3, 601-614.

7. Hansen MF, Jensen SO, Fuchtbauer EM, et al. (2017) High folic acid diet enhances tumour growth in PyMT-induced breast cancer. Br J Cancer 116, 752-761.

8. Pogribny IP, James SJ \& Beland FA (2012) Molecular alterations in hepatocarcinogenesis induced by dietary methyl deficiency. Mol Nutr Food Res 56, 116-125.

9. Lai KG, Chen CF, Ho CT, et al. (2017) Novel roles of folic acid as redox regulator: modulation of reactive oxygen species sinker protein expression and maintenance of mitochondrial redox homeostasis on hepatocellular carcinoma. Tumour Biol 39, 1010428317702649

10. Chagas CE, Bassoli BK, de Souza CA, et al. (2011) Folic acid supplementation during early hepatocarcinogenesis: cellular and molecular effects. Int J Cancer 129, 2073-2082.

11. Guariento AH, Furtado KS, de Conti A, et al. (2014) Transcriptomic responses provide a new mechanistic basis for the chemopreventive effects of folic acid and tributyrin in rat liver carcinogenesis. Int J Cancer 135, 7-18.

12. Lee D, Xu IM, Chiu DK, et al. (2017) Folate cycle enzyme MTHFD1L confers metabolic advantages in hepatocellular carcinoma. J Clin Invest 127, 1856-1872.

13. Cui LH, Quan ZY, Piao JM, et al. (2016) Plasma folate and vitamin $\mathrm{B}_{12}$ levels in patients with hepatocellular carcinoma. Int J Mol Sci 17, 1032.

14. Wu MY, Kuo CS, Lin CY, et al. (2009) Lymphocytic mitochondrial DNA deletions, biochemical folate status and hepatocellular carcinoma susceptibility in a case-control study. Br J Nutr 102, 715-721.

15. Chang SC, Goldstein BY, Mu L, et al. (2015) Plasma folate, vita$\min \mathrm{B}_{12}$, and homocysteine and cancers of the esophagus, stomach, and liver in a Chinese population. Nutr Cancer 67, 212-223

16. Welzel TM, Katki HA, Sakoda LC, et al. (2007) Blood folate levels and risk of liver damage and hepatocellular carcinoma in a prospective high-risk cohort. Cancer Epidemiol Biomarkers Prev 16, 1279-1282.

17. Persson EC, Schwartz LM, Park Y, et al. (2013) Alcohol consumption, folate intake, hepatocellular carcinoma, and liver disease mortality. Cancer Epidemiol Biomarkers Prev 22, 415-421.

18. Peng Y, Dong B \& Wang Z (2016) Serum folate concentrations and all-cause, cardiovascular disease and cancer mortality: a cohort study based on 1999-2010 National Health and Nutrition Examination Survey (NHANES). Int J Cardiol 219, 136-142.

19. Rossi E, Hung J, Beilby JP, et al. (2006) Folate levels and cancer morbidity and mortality: prospective cohort study from Busselton, Western Australia. Ann Epidemiol 16, 206-212.

20. Wolpin BM, Wei EK, Ng K, et al. (2008) Prediagnostic plasma folate and the risk of death in patients with colorectal cancer. J Clin Oncol 26, 3222-3228.

21. McEligot AJ, Ziogas A, Pfeiffer CM, et al. (2015) The association between circulating total folate and folate vitamers with overall survival after postmenopausal breast cancer diagnosis. Nutr Cancer 67, 442-448.

22. Yeh CC, Goyal A, Shen J, et al. (2017) Global level of plasma DNA methylation is associated with overall survival in patients with hepatocellular carcinoma. Ann Surg Oncol 24, 3788-3795.

23. Crider KS, Bailey LB \& Berry RJ (2011) Folic acid food fortification-its history, effect, concerns, and future directions. Nutrients 3, 370-384. 
24. Midttun O, Theofylaktopoulou D, McCann A, et al. (2017) Circulating concentrations of biomarkers and metabolites related to vitamin status, one-carbon and the kynurenine pathways in US, Nordic, Asian, and Australian populations. Am J Clin Nutr 105, 1314-1326.

25. Fang AP, Chen PY, Wang XY, et al. (2018) Serum copper and zinc levels at diagnosis and hepatocellular carcinoma survival in the Guangdong Liver Cancer Cohort. Int $J$ Cancer (Epublication ahead of print version 13 November 2018).

26. Benson AB, 3rd, Abrams TA, Ben-Josef E, et al. (2009) NCCN clinical practice guidelines in oncology: hepatobiliary cancers. J Natl Compr Canc Netw 7, 350-391.

27. Pugh RN, Murray-Lyon IM, Dawson JL, et al. (1973) Transection of the oesophagus for bleeding oesophageal varices. BrJ Surg 60, 646-649.

28. Kamath PS, Wiesner RH, Malinchoc M, et al. (2001) A model to predict survival in patients with end-stage liver disease. Hepatology 33, 464-470.

29. Fedirko V, Duarte-Salles T, Bamia C, et al. (2014) Prediagnostic circulating vitamin D levels and risk of hepatocellular carcinoma in European populations: a nested case-control study. Hepatology 60, 1222-1230.

30. Llovet JM, Bru C \& Bruix J (1999) Prognosis of hepatocellular carcinoma: the BCLC staging classification. Semin Liver Dis 19, 329-338.

31. Zhang CX \& Ho SC (2009) Validity and reproducibility of a food frequency questionnaire among Chinese women in Guangdong province. Asia Pac J Clin Nutr 18, 240-250.

32. Institute of Nutrition and Food Safety CC (2009) China Food Composition (Book 1), 2nd ed. Beijing: Peking University Medical Press.

33. Institute of Nutrition and Food Safety CC (2005) China Food Composition 2004. Beijing: Peking University Medical Press.

34. Willett WC, Howe GR \& Kushi LH (1997) Adjustment for total energy intake in epidemiologic studies. Am J Clin Nutr 65 , 1220S-1228S; discussion 1229S-1231S.

35. Desquilbet L \& Mariotti F (2010) Dose-response analyses using restricted cubic spline functions in public health research. Stat Med 29, 1037-1057.

36. Knol MJ \& VanderWeele TJ (2012) Recommendations for presenting analyses of effect modification and interaction. Int J Epidemiol 41, 514-520.

37. Hosmer DW \& Lemeshow S (1992) Confidence interval estimation of interaction. Epidemiology 3, 452-456.

38. Ito Y, Wakai K, Suzuki K, et al. (2005) Lung cancer mortality and serum levels of carotenoids, retinol, tocopherols, and folic acid in men and women: a case-control study nested in the JACC Study. J Epidemiol 15, Suppl. 2, S140-S149.

39. Lochhead P, Nishihara R, Qian ZR, et al. (2015) Postdiagnostic intake of one-carbon nutrients and alcohol in relation to colorectal cancer survival. Am J Clin Nutr 102, 1134-1141.

40. Harris HR, Bergkvist L \& Wolk A (2012) Folate intake and breast cancer mortality in a cohort of Swedish women. Breast Cancer Res Treat 132, 243-250.

41. Lee TY, Chiang EP, Shih YT, et al. (2014) Lower serum folate is associated with development and invasiveness of gastric cancer. World J Gastroenterol 20, 11313-11320.
42. Galvan-Portillo MV, Onate-Ocana LF, Perez-Perez GI, et al. (2010) Dietary folate and vitamin $B_{12}$ intake before diagnosis decreases gastric cancer mortality risk among susceptible MTHFR 677TT carriers. Nutrition 26, 201-208.

43. Johansson M, Fanidi A, Muller DC, et al. (2014) Circulating biomarkers of one-carbon metabolism in relation to renal cell carcinoma incidence and survival. J Natl Cancer Inst 106, dju327.

44. Dixon SC, Ibiebele TI, Protani MM, et al. (2014) Dietary folate and related micronutrients, folate-metabolising genes, and ovarian cancer survival. Gynecol Oncol 132, 566-572.

45. Ebbing M, Bonaa KH, Nygard O, et al. (2009) Cancer incidence and mortality after treatment with folic acid and vitamin $\mathrm{B}_{12}$. JAMA 302, 2119-2126.

46. Ulrich CM \& Potter JD (2007) Folate and cancer-timing is everything. JAMA 297, 2408-2409.

47. Lee JE, Willett WC, Fuchs CS, et al. (2011) Folate intake and risk of colorectal cancer and adenoma: modification by time. $\mathrm{AmJ}$ Clin Nutr 93, 817-825.

48. Kantor ED, Rehm CD, Du M, et al. (2016) Trends in dietary supplement use among US adults from 1999-2012. JAMA $\mathbf{3 1 6}$, 1464-1474.

49. He YN, Wang Z, Zhao LY, et al. (2017) Dietary intake of vitamins in Chinese population from 2010 to 2012. Ying Yang Xue Bao 39, 112-115.

50. Wang X, Fu J, Li Q, et al. (2016) Geographical and ethnic distributions of the MTHFR C677T, A1298C and MTRR A66G gene polymorphisms in Chinese populations: a meta-analysis. PLOS ONE 11, e0152414.

51. Medici V \& Halsted CH (2013) Folate, alcohol, and liver disease. Mol Nutr Food Res 57, 596-606.

52. Thuesen BH, Husemoen LL, Ovesen L, et al. (2010) Lifestyle and genetic determinants of folate and vitamin $\mathrm{B}_{12}$ levels in a general adult population. Br J Nutr 103, 1195-1204.

53. El-Serag HB (2011) Hepatocellular carcinoma. $N$ Engl J Med 365, 1118-1127.

54. Sieghart W, Pinter M, Hucke F, et al. (2013) Single determination of C-reactive protein at the time of diagnosis predicts longterm outcome of patients with hepatocellular carcinoma. Hepatology 57, 2224-2234.

55. Crider KS, Yang TP, Berry RJ, et al. (2012) Folate and DNA methylation: a review of molecular mechanisms and the evidence for folate's role. Adv Nutr 3, 21-38.

56. Halsted CH, Villanueva JA, Devlin AM, et al. (2002) Folate deficiency disturbs hepatic methionine metabolism and promotes liver injury in the ethanol-fed micropig. Proc Natl Acad Sci US A 99, 10072-10077.

57. Kuo CS, Huang CY, Kuo HT, et al. (2014) Interrelationships among genetic C677T polymorphism of 5,10-methylenetetrahydrofolate reductase, biochemical folate status, and lymphocytic p53 oxidative damage in association with tumor malignancy and survivals of patients with hepatocellular carcinoma. Mol Nutr Food Res 58, 329-342.

58. Lin CC \& Yin MC (2007) B vitamins deficiency and decreased anti-oxidative state in patients with liver cancer. Eur J Nutr 46, 293-299.

59. Kuo CS, Lin CY, Wu MY, et al. (2008) Relationship between folate status and tumour progression in patients with hepatocellular carcinoma. Br J Nutr 100, 596-602. 